\title{
Hospital Social Workers in the US ${ }^{1}$ Helena Lustová
}

\section{Introduction}

Hospital social work has had a long tradition in the US since the beginning of the twentieth century. The overall economic development and social demands influence the form of this type of social work just like any other field. The article introduces the hospital social worker's job in a complex way, putting together economic as well as demographical and some specific, internal factors. While the first part of the article deals with the significant changes over time, the second part faces the current hospital social worker's profile and its relevant issues. Enough space is given to the characteristics of the hospital social worker's duties and responsibilities as well as to the necessary personal qualities and skills. Due to the fact that economic status and financial security have a major importance in the US, the educational necessities and salary options will be introduced as well.

For more than three decades, there has been a long-lasting effort to save money in the US health care system. This, of course, has had an impact on the whole medical field. Significant consequences have been taking place such as reducing numbers of social workers in hospitals, rising pressure in the workplace, and the increasing complexity of the job. Besides the cost-cutting efforts, there are other factors influencing the hospital social worker's job. Those include multicultural and racial matters, the working environment, the size of institutional support, or the lack of evidence-based documentation proving the hospital social worker's efficiency and necessity. All of these matters will be discussed in the relevant context in the last two parts of the article.

\section{The Development of the Hospital Social Worker's Role in Time}

The role of social work and hospital social workers themselves has been changing due to changes in American society. The beginning of the twentieth century brought financial support into the medicinal and health care area. There was a change in the status of hospitals as well. They started to resemble businesses rather than charity settings and the poor became patients or, in more modern language, clients. Naturally, social work within hospitals followed this trend. ${ }^{2}$

At first social work service programmes were helping with identifying patients to relieve the overcrowding of hospitals due to civil war and setting up volunteer units for poor patients. The function of hospital social workers was to help patients as well as to help with organisation in the hospital setting. In a general sense, they had the same working status as nowadays. It was the

1 This article is a part of the project of the specific research GA JU no. 157/2016/H.

2 Cf. (C) Michael REISCH, The Challenges of Health Care Reform for Hospital Social Work in the United States (on-line), Social Work in Heath Care 51 (10), November 2012, pp. 874-875, available at: http://dx.doi.org/10.1080/00981389.2012.721492, accessed $1^{\text {st } J u n e}$ 2017. 
complexity of the job which came later on. ${ }^{3}$

In 1918, the American Association of Hospital Social Workers (AASW) was established and there was a significant rise in number of hospital social work departments as well as an expansion of social workers' roles and duties. Social workers became a helping mediator between the patient and his or her doctor, and at the same time they helped patients to understand their diagnosis and the treatment they were undergoing. ${ }^{4}$

Another important issue was to define the hospital social worker's position towards doctors and hospital staff in general. The growing importance and prestige of physicians led to the tendencies or efforts to treat social workers as subordinates rather than as cooperating members of the hospital teams. ${ }^{5}$

In 1926, there was a split between the social workers who work with medical doctors and the social workers who work with psychiatrists followed by the conference of AASW in 1929 where the most important job duties of hospital social worker were expressed. Those included medical-social diagnosis and its interpretation, teamwork, casework, discharge planning, financial solutions for the chronically ill and disabled, and several others. Psychiatric social workers later established their own organisation, the American Association of Psychiatric Social Work (AAPSW). ${ }^{6}$

Since World War I, hospital social workers have followed the trend of forming group practices like those created by physicians. These include several different specialists in the field and enable to work with patients in more flexible and holistic way. ${ }^{7}$

In the early 1950s, all national social organisations merged into the new National Association of Social Workers (NASW). Due to the specialised knowledge of the medical field, it was not an easy decision for hospital social workers existing at that time under AAMSW (American Association of Medical Social Workers). The newly formed NASW's goals were making the social profession even more professionalised and formalised. ${ }^{8}$

Another event that was very important in American health care history in general was the establishing of Medicare and Medicaid, which occurred in 1965. The founding of these federal programmes (which financially ensured health care for the elderly and the poor) caused an increase in these kinds of patients in hospitals and the further development of social hospital work as well. ${ }^{9}$ In the 1970s, hospital social work became more and more specialised, following the general trend in medicine. The efforts of proving the efficiency and productivity of social work praxis in numbers appeared. How to go about measuring social work has been a very important question, mainly because of the topic of its usefulness and either the indispensability or dispensability of social workers in hospitals. These discussions arose in the 1980s and it has been this way since then. The main reason was due to attempts to reduce the costs of health care and these discussions have continued to last into the present. Naturally, the circumstances put more pressure on hospital social workers and have diminished their influence, mainly because there has been a significant drop in the number of them in administrative and managerial areas. Because of this, the workload of an individual hospital worker has increased. ${ }^{10}$

3 Ibid., p. 875.

4 Ibid., p. 876. Cf. also (C) Sharon M. KEIGHER, Knowledge Development in Health \& Social Work (on-line), Health \& Social Work 25 (1), February 2000, pp. 3-8 (on-line), available at: https://doi.org/10.1093/hsw/25.1.3, accessed $1^{\text {st }}$ June 2017.

Cf. (C) Michael REISCH, The Challenges..., p. 877.

Cf. (C) Michael REISCH, The Challenges..., p. 877. Cf. also @ Sharon M. KEIGHER, Knowledge...

Cf. (C) Michael REISCH, The Challenges..., p. 877.

Cf. (C) Michael REISCH, The Challenges..., p. 878. Cf. also (C) Sharon M. KEIGHER, Knowledge...

Cf. (C) Michael REISCH, The Challenges..., p. 878.

10 Ibid., p. 879-880. Cf. also CTRUITY, Social Worker (on-line), available at: https://www.truity.com/career-profile/social- 


\section{The Current Profile of the Hospital Social Worker}

\subsection{Job Characteristics}

The hospital social worker helps the patients and their families to address and solve the physically, socially, and economically difficult situation and problems connected with the patient's health condition. His or her specialisation within a hospital varies and generally correlates with the hospital departments. ${ }^{11}$ Their job duties include the following areas.

- Medical-social diagnosis: The hospital social worker helps patients to understand their medical condition and treatment options and prepares them for the consequences of various treatments or for treatment refusal. Consequently, he or she helps them to make those necessary changes in their lifestyle. ${ }^{12}$

- Team work: The hospital social worker cooperates with doctors, nurses and other health care professionals. He or she informs them and helps them to consider the effect of the patient's physical condition on his or her mental health or emotional state. ${ }^{13}$

- Case work: This includes a follow up with patients during their case. The social worker should ensure himself or herself about the improvement of the patient's situation in the future. This duty is connected with the evaluation of services provided by hospital social workers. The effective outcomes should be ensured for a positive job status as well. ${ }^{14}$

- Discharge planning: The hospital social worker prepares patients for the transition from hospital settings back to their homes, communities and (in case of serious illness or dying patients) to the alternative facilities such as hospices or specialised clinics. He or she provides for transportation, arranges for in-home medical equipment, and coordinates the follow-up treatments. He or she cooperates with the service provider agencies in order to develop a care plan for a patient if necessary. He or she gives patients and their families the information about various services such as home health care or support groups in their local community. ${ }^{15}$

Long, chronic or serious illnesses are usually connected with high medical expenses and (even if some patients have the insurance coverage) the out-of-pocket expenses could be significant. The hospital social worker can deal with those financial problems by helping patients to apply for benefits provided by Medicaid or other types of government or community support. In other words, he or she should be able to arrange for resources to finance the medication and services which are needed. ${ }^{16}$

\subsection{Personal Skills and Qualities}

The hospital social worker's job can be challenging and psychologically very demanding. The hospital social worker meets people in stressful, difficult situations. These are often seriously ill and

worker, accessed $1^{\text {st }}$ June 2017.

11 Cf. (C) NASW Center for Workforce Studies \& Social Work Practice, Social Workers in Hospitals \& Medical Centers, occupational profile (on-line), available at: http://workforce.socialworkers.org/studies/profiles/Hospitals.pdf, accessed $1^{\text {st }}$ March 2017.

12 Cf. (OTRUITY, Social Worker... Cf. also C NASW Center...

13 Cf. (C) NASW Center... Cf. also @ TRUITY, Social Worker..

14 Cf. CTRUITY, Social Worker...

15 Ibid. Cf. also (C) EDUCATIONAL COMMISION FOR FOREIGN MEDICAL GRADUATES. Health Care Team, Care and Psychosocial Support Coordinators, Medical Social Worker (contributed by Nancy A. MORROW) (on-line), available at: http://www.ecfmg.org/ echo/team-psych-msw.html, accessed $1^{\text {st } J u n e ~} 2017$.

16 Cf. (C) NASW Center... Cf. also (C) EDUCATIONAL COMMISION... Cf. also CTRUITY, Social Worker... 
have to deal with the consequences of their health condition. To be able to successfully manage the job a hospital social worker should possess certain qualities and skills, such as:

- Compassion and empathy - for understanding problems of people and the ability to develop a trustworthy relationship with them. In addition to these qualities, a hospital social worker has to be able to listen to the patients' needs. ${ }^{17}$

- Organisational and time-management skills - the ability to help and manage caseloads. The medical social worker takes care not only of his or her own documents, but they often assist and guide the patients with their paperwork as well. Due to there usually being a large number of patients, a medical social worker must efficiently manage his or her time in order to provide help for all of them equally and fairly. ${ }^{18}$

- Problem-solving skills - to be able to deal with patients' problems. A hospital social worker has to be an advocate for patients and stand by them. He or she needs to find an effective solution for many specific situations connected with patients' health conditions. ${ }^{19}$

\subsection{Education and Salary}

The basic educational requirement for a job in a social work area (including the hospital social work area) is a bachelor's degree. However, for the majority of medical facilities a master's degree in social work is the best option. The job training includes lots of hours in praxis. The practical part of the studies is called a field placement. ${ }^{20}$

As soon as an individual has successfully gained his or her master's degree, he or she can become a licensed social worker. In order to obtain the license, one has to fulfil the conditions and requirements of the state in which he or she wants to work. The standards for licensing vary; there is a tendency to place emphasis on communicative skills, professional ethics, and an awareness of cultural diversity. ${ }^{21}$ The requirements of individual states are provided by the Association of Social Work Boards. ${ }^{22}$ These also include a specific number of supervised working hours and this supervision must be done by a licensed social worker. The license is not mandatory, though, for some hospitals or other medical facilities hire social workers who are still in the process of working on their certification. ${ }^{23}$ On the other hand, most insurance providers require the license in order to be willing to reimburse for services.$^{24}$ Hospital social workers further specialise according to specific hospital areas - emergency, oncology, paediatrics, nephrology, neurology, etc. ${ }^{25}$ The salaries for hospital social workers depend on their education, location, the area of practice and their years of experience. Focusing on education, a hospital social worker with a master's degree earns approximately $30 \%$ more ( $\$ 60,000$ median) than his or her colleagues with a bachelor's degree at only ( $\$ 40,000$ median). The newest 2016 U.S. Bureau of Labor Statistics shows that an annual mean wage for social workers in general medical and surgical hospitals is $\$ 61,080$. The annual salaries vary significantly by region as well. Hospital social workers in the western part of

17 Cf. CTRUITY, Social Worker...

18 Cf. CTRUITY, Social Worker...

19 Ibid. Cf. also (C) EDUCATIONAL COMMISION...

20 Cf. (C) EDUCATIONAL COMMISION...

21 Ibid.

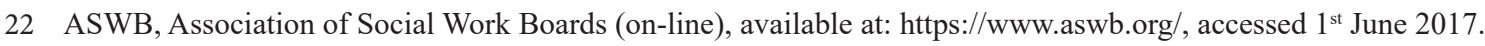

23 Cf. (C) Stephanie BEDFORD, The Role of a Medical Social Worker (on-line), available at: https://www.gapmedics.com/blog/2015/06/17/ the-role-of-a-medical-social-worker/, accessed $1^{\text {st }}$ June 2017.

24 Cf. (C) EDUCATIONAL COMMISION...

25 Cf. C BEDFORD, The Role of... 
the US earn $\$ 67,700$ (median) while their counterparts in the Midwest earn only $\$ 55,000$ (median). Regarding differences according to practice area, the highest annual salaries are in administration (\$92,000 median). Length of experience has an evident impact on hospital worker salaries as well. The hospital social worker with less than nine years of practice earns annually $\$ 52,000$ (median) while one with more than 20 years of practice earns $\$ 64,900$ (median). ${ }^{26}$

\section{The Value and Negative Aspects of the Job (a review of two research studies)}

\subsection{The Value of Social Work in Hospitals}

As health care spending has been constantly on the rise, hospital administrators often view social workers and their work as expendable. There has been pressure to prove the cost-effectiveness of social work in hospitals. On the other hand, the hospital infrastructure has to allow the collaboration and utilisation of data that can support and prove the need for hospital social work. For example, tracking the successes of discharge processes could be the way of showing and proving the efficiency of hospital social workers. ${ }^{27}$

Charles Aurebach, Susan E. Mason and Heidi Heft La Porte did a research study to prove there to be a more quality outcome with patients being served by social workers in comparison with patients treated without social workers' help. Their study reviews the two-year data set documenting social work activities on medical-surgical units of a large medical centre. ${ }^{28}$

The data shows that 64,722 patients were admitted to the hospital medical-surgical area within two years (2002-2004) and $15.7 \%$ of them were served by social workers. The mean age of patients with social work assistance was higher (68.8) in comparison with others (53.8). Those patients with social work service had a significantly higher length of stay (11.4 days) in comparison with those without this service (4.3 days). The most frequents services provided to patients were assessment $(85.7 \%)$, discharge planning (80.7\%), hospital staff cooperation (67.8\%), health education (33.3\%), individual counselling (23.7\%), family counselling (33,0\%), and financial counselling (18.5\%). ${ }^{29}$

As the age and complexity of the social services provided show us, social workers are assigned to the most difficult cases. Those cases would be problematic to solve without effective social work involvement. Thus, those facts suggest that seeing hospital social workers as expendable is inadequate. Hospital social workers are trained to solve a combination of physical, mental and social issues that are out of the range of the usual diagnostic numbers and facts. ${ }^{30}$

\subsection{Negative Aspects Influencing Hospital the Social Worker's Job}

The hospital social worker deals with the sick that are often in a very difficult situation suffering physically, emotionally, or even socially on a daily basis. As was mentioned before, social workers are intensively prepared for the possible obstacles during their studies and practice. On a longterm basis or with a different hospital environment, some negative working aspects might arise. The 2007 study by Connie Urlich, Patricia O’Donell, Carol Taylor, Adrienne Farrar, Marion Danis

26 Cf. (C) NASW Center... Cf. also (C) U.S. Bureau of Labor Statistics, Occupational Employment Statistics, Occupational Employment and Wages, May 2016 (on-line), available at: https://www.bls.gov/oes/current/oes211022.htm, accessed 1 ${ }^{\text {st }}$ June 2017.

27 Cf. (C) Charles AUERBACH - Susan E. MASON - Heidi HEFT LAPORTE, Evidence that Supports the Value of Social Work in Hospitals (on-line), Social Work in Heath Care 44 (4), 2007, pp. 17-18, 23, available at: http://dx.doi.org/10.1300/J010v44n04_02, accessed $1^{\text {st }}$ June 2017.

28 Ibid., p. 17.

29 Ibid., pp. 23-24, 27.

30 Ibid., pp. 27-30. 
and Christine Grady investigated the reference frame of several work factors (ethical climate and ethical stress, job satisfaction and the intention to leave one's job) among nurses and social workers in the United States. Questionnaires were sent to 1215 randomly selected nurses and social workers in four census regions of the United States. The results and following discussions can be presented within the following three parts. ${ }^{31}$

- Ethical stress and its consequences - 32.5\% of respondents felt powerless and 34.7\% overwhelmed with ethical issues at their workplace. Those frustrated were $52.8 \%$ and $40 \%$ felt fatigue when unable to solve ethical issues. Almost two thirds of respondents confirmed that there are some ethical issues which cannot be influenced. ${ }^{32}$

- The differences. Racial and cultural trends - hospital social workers expressed more ethical stress than their counterparts from other settings. This fact could be influenced by the greater size of the hospital settings, and thus by the higher number of staff and patients. Regarding racial differences, African-American nurses felt less satisfied than their white colleagues. In multicultural American society with its changing demographical trend, racial and cultural issues will have to be addressed. This matter will be dealt with in the last part of this article introducing future trends in hospital social work. ${ }^{33}$

- Working environment and institutional support - the working environment contributes strongly to one's attitude toward the job. An overall positive climate and job satisfaction worked against the intention of correspondents to leave their jobs. Being a respected and valued member of the team is more influential than staffing patterns and salaries, which are often overestimated by traditional economic models. Institutional support correlates with ethical stress as well. Social workers are trained to recognise, address and deal with ethical stress. Sadly, with no support and respect in their workplace, their ability cannot be adequately used. On the other hand, with a supportive environment social workers are able to deal with much higher ethical stress while still being happy with their job. Consequently, overall job satisfaction has a significant effect on care and its quality and, in this sense, on spending as well, which is crucial. ${ }^{34}$

\section{The Current Situation and Possible Trends for Hospital Social Work}

In the final part of this article, let me introduce the current situation of hospital social work and its possible future in general social and political contexts. The most influential seems to be the financial issues, specifically, the long-lasting effort to reduce the health care spending and its impact, and the future demographical changes in the US population.

After the 2016 presidential elections and transition of political powers in the US government, the future of health care reform is still unclear. The intention to save money in the health care industry has been strong since the spending is enormous and at the highest worldwide. As already mentioned in chapter one, there have been the consequences of those cost-cutting efforts in the hospital, for the social workers mainly in management, and the administration area. On the other hand, the workload of a single hospital social worker is increasing. One of the specific reasons for tight hospital budgets for social workers is reduced Medicare payments to hospitals. Medicare is

31 Cf. C Connie ULRICH - Patricia O'DONNELL - Carol TAYLOR - Adrienne FARRAR - Marion DANIS - Christine GRADY, Ethical Climate, Ethics Stress, and the Job Satisfaction of Nurses and Social Workers in the United States (on-line), Social Science \& Medicine 65 (8), October 2007, pp. 1708-1719, available at: https://doi.org/10.1016/j.socscimed.2007.05.050, accessed $1^{\text {st } J u n e ~} 2017$. 
a federal programme ensuring coverage for elderly Americans. During the processing of the 2010 health care reform, Medicare's budget was lowered in order to broaden coverage for more uninsured Americans. As elderly people represent a significant part of hospital patients and social workers' clients, these Medicare cuts could have the financial impact on hospital social work as well. ${ }^{35}$ Despite the efforts, health care spending is still on the rise and many Americans are dealing with their medical bills. Thus, the duties of a hospital social worker connected with financial advising and counselling will be on the rise. As the budget limitations for hospitals have been diminishing along with the number of managerial and administrative staff, it will definitely increase the need for self-care and self-monitoring among social workers in practice for the future. ${ }^{36}$

Talking about future and possible trends in US society for hospital social work, a lot of influence could be had by a changing demographical trend in the US population and its effect. While in 1980 there was $11.3 \%$ of population above 65 , the expected number in 2020 is $16.3 \%$, and $20.4 \%$ in 2040. Whereas the percentage of seniors is growing, the population of people from 0 to 19 years old is declining (from $31.9 \%$ in 1980 to $25.9 \%$ according to the prediction for 2040). Elderly people tend to need more health care. In addition, due to a longer life expectancy, the majority of those elderly will be white. Such a change could bring more intercultural and racial issues. ${ }^{37}$

All of the duties of hospital social workers are likely to increase and become even more complex due to the social changes and budget difficulties in the health care area. In addition, he or she will have to become more sensitive to intercultural and racial matters. All of those mentioned circumstances also bring the question of how to attract and retain staff with professional skills and personal qualities for the job. For this issue, the need for improving working conditions will arise even more intensively. Furthermore, due to the prevailing financial troubles, hospital social workers will have to manage the evidence-based outcome assessment to clearly demonstrate their economic importance and value for patients, hospitals, and the whole society. ${ }^{38}$

\section{Conclusion}

The future of hospital social work depends on general factors, as well as on specific ones. Among the general elements, the future of US health care reform and its subsequent financial solutions are the most important. Whether the system will be almost completely private or some of the federal programmes like Medicare and Medicaid will stay, it is determined by the current president Trump and his administration. The specific factors for the hospital social worker's job (which are crucial) include the cooperation of the hospital social workers themselves with hospitals and relevant institutions on establishing:

- the evidence-based outcome assessment - in order to prove the value and efficiency of the job;

- the professional preparation for the future demographical and culture-racial changes in the population;

- the quality teamwork in the workplace among social workers, doctors, nurses and the hospital

35 Cf. (C) Michael REISCH, The Challenges..., pp. 879-880. Cf. also Lloyd LIM, Beyond Obamacare. Solving the Healthcare Cost Problem, Mustang, Oklahoma: Tate Publishing \& Enterprises, LLC, 2014, p. 15. Cf. also (C) Robert E. MOFFIT, Year Six of the Affordable Care Act: Obamacare's Mounting Problems (on-line), BACKGROUNDER, 3109, April 2016, available at: http://www. heritage.org/health-care-reform/report/year-six-the-affordable-care-act-obamacares-mounting-problems, accessed $1^{\text {st }}$ June 2017 , pp. $12-13$.

36 Cf. (C) Robert E. MOFFIT, Year Six..., pp. 8-10. Cf. also (C) Michael REISCH, The Challenges..., p. 888.

37 Cf. (C) Michael REISCH, The Challenges..., pp. 883-884.

38 Ibid., p. 888. 
staff in general;

- the educational and practical preparation of hospital social workers including the development of their independency, self-care, and self-monitoring skills;

- the improvement of the working environment in order to retain staff with professional skills and high personal qualities necessary for the job, and the institutional support for social workers and nurses to be able to cope with the working stress and other negative psychological issues.

\title{
Hospital Social Workers in the US
}

\begin{abstract}
The article is addressed to a wide range of readers, from the public unfamiliar with the topic of social work generally to the experts who have not had a chance to know the specifics of hospital social work in the United States. The goal is to provide an up to date overview of the subject in the current post-presidential election climate. The article does not provide a deep analysis of social work methods. It rather analyses the selected characteristics that are important for defining the hospital social worker's current and future role in the US health care system. It briefly describes the development of the hospital social worker's status and his or her duties since the beginning of the twentieth century, the current job characteristics, and the educational necessities. It also compares their salaries in different regions in the US. The same method is used when dealing with the value of the hospital social work and the negative aspects of the job. Two research studies are introduced and the results of each are compared in order to prove and understand those issues. In the last part of the article, the current situation in the health care area is briefly described, focusing on the consequences of the cost-cutting political efforts for hospitals. Future demographical, cultural and racial issues in the US are brought up and the predicted figures are compared with the past ones. Those are put into the context with the hospital social worker's current and expected future role in the health care area. The conclusion synthesises used data and information and put forward the crucial changes needed in the future hospital social work field.
\end{abstract}

Key words: hospital social worker, role, skills, qualities, salary, value, stress, cooperation, trends, costs

\section{Author contact \\ Helena Lustová MA}

University of South Bohemia in České Budějovice Faculty of Theology, Department of Ethics, Psychology and Charity Work Kněžská 8, 37001 České Budějovice lustova@tf.jcu.cz 